\title{
O mito e o nascimento da filosofia
}

\author{
The myth and birth of philosophy
}

\author{
BRUNO NASCIMENTO OLIVEIRA ${ }^{1}$
}

\begin{abstract}
Resumo: Neste artigo abordaremos o conhecimento filosófico que surgiu aos poucos, em substituição aos mitos e às crenças religiosas, na tentativa de conhecer e compreender o mundo e os seres que nele habitam. A formação do pensamento filosófico se deu na passagem do mito (mýthos) para a razão (lógos). Os deuses têm sua importância relativizada pela razão a partir dos elementos existentes na natureza estudados pelos pré-socráticos. Este artigo abordará alguns elementos do discurso mítico levando em consideração o indício de "dobra" das formas de pensar que se adaptaram até sua forma sistematizada que chegaram até nós.
\end{abstract}

Palavras chave: Mito. Razão. Formação.

Abstract: In this article we will discuss the philosophical knowledge that the few people, in substitution of the myths and the religious beliefs, try to know and what is the world and the beings that inhabit it. A formation of philosophical thought occurred in the passage from myth (mýthos) to reason (logos). The gods have their importance relativized for reason from elements existing in nature studied by the pre-Socratics. This article will address some elements of mythical discourse leading to considerations of the "fold" clue of ways of thinking and have adapted to their systematized form that suits us.

Keywords: Myth. Reason. Formation.

\section{Introdução}

A mitologia nas sociedades antigas, representava uma forma de compreensão dos fenômenos naturais, os povos antigos inseriram em sua cultura narrativas de deuses cultuados que assumiam formas e personalidades humanas, onde os homens dedicavam um templo de adoração para cada deus que a cidade adorasse, porém nas cidades gregas, poderiam haver inúmeras divindades e narrativas míticas, das quais chegaram até nós.

Então a mitologia como um processo de formação da humanidade sofreu adaptações e transformações ao longo do tempo, além de influências de novas culturas através do helenismo. A mitologia como uma forma de pensamento não sistematizado e aberto recebeu essas influências e se renovou. Se entendemos a mitologia como uma forma de pensamento não sistematizado, baseado no pensamento não racional, e com base no senso comum, não podemos nos esquecer de que esse tipo de pensamento é que possibilitou ao longo da história o desenvolvimento do pensamento crítico e sistematizado.

${ }^{1}$ Acadêmico de Filosofia - Universidade Estadual do Piauí. Bolsista do Projeto Institucional de Bolsa de Iniciação à Docência - PIBID. E-mail: brunophbo8@gmail.com. 
Em síntese, o ponto de partida da filosofia é o senso comum, sem ele não haveria filosofia como a conhecemos hoje, nem ao longo de sua história principalmente a partir da figura de Sócrates (469-399 a.C.), Platão (427-347 a.C.) e Aristóteles (384-322 a.C.). Sem anteriormente não ter passado por um período de amadurecimento do processo racional.

Após toda eclosão do pensamento mítico, o mito não já não conseguia cumprir sua função de educar e explicar fatos da vida humana, é nesse momento que surge do culto a divindades e do enfraquecimento dos mitos antigos a tragédia grega, por meio do teatro da Grécia antiga.

A tragédia grega surgida do culto ao deus Dioniso, um semideus. Teve como seus maiores representantes três escritores, ou comumente chamados de tragediógrafos, são eles: Ésquilo (525-524 a.C.), Sófocles (496-406 a.C.) e Eurípedes (480-406 a.C.) dos quais nos restaram poucas obras, mas que são o suficiente para em primeiro momento compreender a graciosidade da tragédia grega tinha como "ferramenta de trabalho" os mitos em seu estado bruto. Os tragediógrafos readaptavam o mito e os apresentavam em competições teatrais, que duravam dias e todos os indivíduos da pólis poderiam assistir.

A tragédia grega consistia em "fabular" os mitos e lhe fornecerem características novas que pudessem ensinar temas diversos para o público, sejam eles, religiosos, familiares, morais ou políticos. Para esse feito os tragediógrafos se utilizam de vários elementos poéticos que traduzem o cerne dos acontecimentos da Grécia antiga e compõem a grandeza da tragédia como um instrumento de educação do povo grego.

Desse modo, podemos afirmar que, a mitologia e a tragédia grega, preparam o "terreno" para o pensamento filosófico surgido na Grécia antiga. Elementos como "origem" e "princípio", estão presentes tanto nos discursos clássicos, por exemplo em Homero e Hesíodo, como em outros poetas e pensadores da filosofia. A questão da "origem", [åpXń] arché, está presente também em pensadores do período chamado présocrático ou período dos naturalistas; estes pensadores postularam a unidade das coisas constituídas por um princípio comum a tudo que existe.

Por toda história da filosofia, seja na figura de Platão ou Aristóteles eles fizeram referência aos enredos trágicos, principalmente Aristóteles caracterizou a tragédia como experiência poética e filosófica e dedicou uma obra $A$ poética para falar de suas características e composições.

Elementos como o a hybris, hamartia, catarse, páthos, reconhecimento, peripécia, nó e desenlace fazem parte da estrutura da tragédia que se anelam a seu enredo, elevando a tragédia para uma nova forma de pensamento na Grécia antiga especificamente. Compreender essa estrutura presente na tragédia grega e nos mitos antigos se torna uma tarefa essencial para compreender a construção conceitual das novas formas de pensar ao longo da história e notar como essas novas maneiras de 
pensar modificaram o homem moderno, porém esse homem moderno não está em sua totalidade desvinculado do antigo.

Portanto, devemos no atentar para todos os elementos presentes neste trabalho, pois somente através desse retorno ao passado é possível fazer uma tarefa basilar para a filosofia, o conhecer a si mesmo, rever o surgimento dos mitos antigos e perceber como sua evolução se deu em torno do ocidente é fundamental para compreendermos as formas de educação do povo antigo, e como isso nos atingiu e nos atinge ainda hoje, por isso a máxima socrática do conhece-te a ti mesmo, é sempre atual. Compreender o nosso passado para que possamos entender o presente.

\section{O mito e o nascimento da filosofia}

Nas definições mais comuns sobre o nascimento da filosofia, geralmente se concebe o seu surgimento a partir do rompimento entre "mito" e "logos": "no entanto, nela é tão estreita a interpretação do elemento racional e do "pensamento mítico", que mal se pode separá-los" (JAEGER, 2013, p. 191). Nesse sentido, vemos que o "milagre grego", ou seja, a ruptura entre o pensamento mítico e o pensamento racional, não difere tanto entre si, pois o mito se apresenta como correlato a filosofia, dado que, o fundamento filosófico "cunhado" pelos gregos reside na observação do mundo natural sensível. Essa será também a abordagem expressa por Heráclito, um dos primeiros filósofos da Grécia Clássica, em seus fragmentos sobre a natureza ele afirma:

Este Logos, os homens, antes ou depois de o haverem ouvido, jamais o compreendem. Ainda que tudo acontece conforme esse Logos, parece não terem experiência experimentando-se em tais palavras e obras, como eu as exponho, distinguindo e explicando a natureza de cada coisa. Os outros homens ignoram o que fazem em estado de vigília, assim como esquecem o que fazem durante o sono (BORNHEIN, 1998, p. 36).

Acima Heráclito nos adverte para a observação do mundo natural, onde tudo que nos é apresentado representa uma unidade primordial e para pensarmos o mundo, porém diante disso, os homens não atentam para este fato, de que todos os fenômenos físicos, ou seja, o mundo natural, reproduz uma unidade de mundo que pode ser pensada através de um Logos "consciente" no que se refere a singularidade do universo.

As explicações das observações das coisas sensíveis, ou seja, as narrativas "não argumentativas" chegaram até nós através dos poemas de Homero, além das narrativas de Hesíodo que trata da origem dos deuses: "os mitos sobre o nascimento do mundo. É nesse momento que assistimos ao aparecimento da filosofia científica” (JAEGER, 2013, p. 197).

Observa-se que os poetas nos forneceram as bases dessa investigação racional, orientada pela filosofia, pois, na tentativa de explicar a origem e o movimento das 
coisas naturais (o mundo sensível) utilizaram-se da fábula e do mito, para possibilitar o surgimento dessa filosofia científica antiga. Este foi o artifício usado pelos poetas, para envolver elementos místicos que trabalham com a noção de sentido arcaico, que aponta para o princípio, ou seja, indicam a noção de arché, como sendo a base: "de um princípio inaugural, constitutivo e dirigente de toda a experiência da palavra poética" (TORRANO, 1995, p. 15).

A arché ligada ao sentido requerido por Hesíodo possui uma relação de verossimilhança com a preocupação dos primeiros filósofos, que consiste na preocupação com o elemento primário que constitui todas as coisas. Na tradução de Torrano (HESÍODO,1995, p. 92) temos a seguinte narrativa sobre o início do mundo:

Sim bem primeiro nasceu Caos, depois também

Terra de amplo seio, de todos sede irresvalável sempre,

Dos imortais que tem a cabeça do Olimpo nevado (...)

Primeiro nasceu o Caos, segundo Hesíodo após esse inefável nascimento, a Terra, resultado desse Caos, deu origem a genealogia olímpica. Toda a poesia hesiódica é marcada por uma linhagem genealógica que nada mais é que a tentativa de estabelecer as bases da origem do mundo e das coisas, portanto, para Hesíodo deveria existir uma causa primaria (arché) que forneceria a condição de possibilidade para formar e ordenar todas as coisas. Na geração olímpica, os deuses também possuem características específicas, as quais destacam a força vital única de cada um:

[...] o vasto quadro numinoso descrito na Teogonia. Todas as divindades geradas têm cada qual a sua distinção frente as demais. A singularidade é expressa por um nome (por exemplo, Atena) e por epítetos (por exemplo, "de olhos glaucos") que exprimem sua potencialidade, sua natureza intrínseca (JARESKI, 2015, p. 45).

Diferentemente do Proêmio de Hesíodo, os fragmentos e comentários a respeito da preocupação com o problema da origem, em filósofos conhecidos como présocráticos, aponta para uma mudança que retira a genealogia olímpica da explicação da origem do mundo, mas que mantém a causa primária de todas as coisas, como nos diz Aristóteles:

Tales o fundador deste tipo de filosofia, diz que o princípio é a água (por este motivo afirmou que a Terra repousa sobre a água), sendo talvez levado a formar essa opinião por ter observado que o alimento de todas as coisas é úmido e que o próprio calor é gerado e alimentado pela umidade: ora, aquilo de que se originam todas as coisas é o princípio delas. Daí lhe veio esta opinião, e também de que as sementes de todas as coisas são naturalmente úmidas e de ter origem na água a natureza das coisas úmidas (ARISTÓTELES, 1969, p. 42).

É com Aristóteles que a noção de arché ganha força, ou seja, ao procurar um substrato material para todas as coisas o filósofo de Estagira percorre o mesmo 
"caminho" que os poetas e os pré-socráticos percorreram, embora a preocupação de Aristóteles estivesse voltada para a construção de uma teoria das causas. A premissa que reside na evolução das causas é que deve existir um princípio unitário e formativo de tudo que existe, nos diz Aristóteles (1969, p. 43): "De tudo isto poderia concluir-se que a única causa é a chamada causa material; à medida que os homens foram progredindo neste terreno, os próprios fatos lhe abriram o caminho, constrangendo-os a prosseguir na investigação”.

Tales é apontado como o primeiro a pensar no problema filosófico da origem, em um período de consciência da existência de um Logos, por isso, é com o filósofo de Mileto que ocorre a primeira tentativa de designar alguma definição da origem, como começo ou fase inicial, pois, o filósofo pensa a respeito de um princípio, e também de um fundamento (arché), considerando que sua preocupação estava em algo já determinado e ordenado:

[...] Tales de Mileto, filho de Examias, e Hipão, que parece ter sido ateu, afirmava que água é o princípio, tendo sido levados a isto pelas (coisas) que lhes apareciam segundo a sensação; pois o quente vive com o úmido, as coisas mortas ressecam-se, as sementes de todas as coisas são úmidas e todo alimento é suculento. Donde é cada coisa, disto se alimenta naturalmente: água é o princípio da natureza úmida e é continente de todas as coisas; por isso supuseram que a água é o princípio de tudo e afirmaram que a terra está deitada sobre ela. Os que supõem um só elemento afirmam-no ilimitado em extensão, como Tales diz da água (REGIS, 1996, pp. 40-41).

Antes vejamos como Tales, segundo Aristóteles, recuperou a tese de criação do universo e pensou a água como princípio constituinte de todas as coisas:

Pensam alguns que os próprios Antigos, que viveram muitos antes das gerações de agora e foram os primeiros a discorrer sobre os deuses, tinham uma concepção semelhantes da natureza; pois eles faziam de Oceano e de Tétis os pais da criação e afirmavam que os deuses tomavam a água por testemunha de seus juramentos, chamando-lhe Estige. Com efeito, o mais antigo é o mais venerável, e o mais venerável é aquilo por que se jura (ARISTÓTELES, 1969, p. 42).

De fato, nos versos de Homero ele nos informa que a gênese de todos os seres é o "Oceano":

Hera, a quem muito venero, nascida de Zeus poderoso, A qualquer outro dos deuses, dotados de eterna existência, Adormecera de grado, ainda mesmo que fosse a corrente Do rio Oceano, que é a origem primeira de todos os seres (...) (ILÍADA, 2015, vv. 243-246).

O problema da origem e sua relação com o princípio em sua acepção, da qual, estamos aqui trabalhando no diz Jaeger (2013, p. 193) que: 
A única diferença reside no fato de a concepção do Estado Ser, pela sua própria natureza, de caráter imediatamente prático, ao passo que a investigação da phýsis, ou gênese, isto é, "origem", é impulsionada pela "teoria". O problema do homem não foi encarado pelos gregos, a princípio, do ponto de vista teórico. Mais tarde, nos estudos dos problemas do mundo externo e particularmente da Medicina e da Matemática, é que se descobriram intuições do tipo de uma téchne exata, que serviram de modelo para a investigação do Homem interior.

Portanto, Tales formulou que a arché, designaria um fenômeno sensível, ou seja, observável, através dos sentidos ele estabeleceu a água como elemento primordial empírico, desse modo, a arché designaria um elemento comum observável em todas as coisas, visto que, para ele, através dos sentidos a água e o úmido, representa-se como sendo o elemento universal que constitui e torna possível, o princípio, ou seja, a explicação de todos os fenômenos físicos, que aparentemente, por meio da água reside e transforma-se possibilitando o surgimento a partir de um todo, o múltiplo.

Anaximandro (610-547 a.C) de Mileto propôs uma definição para o problema da origem, e consequentemente da arché, porém, sua definição, assume um ponto de vista da "metafísica" tornando ainda mais abstrata, a origem ou princípio de todas as coisas.

Nesse sentido:

Dentre os que afirmam que há um só princípio, móvel e ilimitado, Anaximandro, filho de Praxíades, de Mileto, sucessor e discípulo de Tales, disse que o ápeiron (ilimitado) era o princípio e o elemento das coisas existentes. Foi o primeiro a introduzir o termo princípio. Diz que este não é a água nem algum dos chamados elementos, mas alguma natureza diferente, ilimitada. E dela nascem os céus e os mundos neles contidos [...] (REGIS, 1996, p. 48).

A concepção de princípio de Anaximandro não reside em nenhum elemento empírico, contrariando assim, a concepção de Tales, para o qual, a água consistiria nesse elemento primordial. Portanto, a principal característica do que Anaximandro chamou de ápeiron é sua indeterminação: "Anaximandro [...] afirmou que o princípio e elemento era o infinito, sem defini-lo como ar, ou água, ou qualquer outra coisa. Disse também que as partes sofrem mudanças, porém o todo é imutável" (DIÓGENES LAERCIO, 2008, p. 47).

Em suma, o ápeiron engloba a arché em uma relação de afirmação enquanto princípio constituinte do mundo, como forma, ou tentativa de descrever uma possibilidade ontológica fundamental do mundo e de todos os seres. Anaximandro pensa o ápeiron não, tão somente, como começo da filosofia, mas como continuação e autoafirmação da filosofia enquanto pensar metafísico: "mas não se trata de uma simples uniformidade do fluxo causal, no sentido abstrato da nossa ciência atual. $\mathrm{O}$ que Anaximandro formula com as suas palavras é mais uma norma universal do que uma lei da natureza no sentido moderno" (JAEGER, 2013, p. 202). 
Trata-se de uma norma universal, de algo que em sua unidade compõe, inúmeros mundos possíveis, ou seja, o ápeiron é o ilimitado do pensar sobre o fenômeno do mundo e das coisas, é sobre essa unidade que:

Heráclito afirma a unidade de todas as coisas: do separado e do não separado, do gerado e do não gerado, do mortal e do imortal, da palavra (logos) e do eterno, do pai e do filho, de Deus e da justiça). É sábio que os ouviram, não a mim, mas as minhas palavras (logos), reconheçam que todas as coisas são um. (BORNHEIM, 1998, p. 39).

Por isso, todo o fundamento mítico e poético baseia-se no pensar empírico que se transforma em um pensar para além do mundo sensível. Assim o pensar mítico não se encerra na filosofia pré-socrática, muito pelo contrário, sugerimos que ela deve ser entendida como extensiva ao pensar mítico.

O grande problema é que normalmente a discussão sobre essa temática consiste na tentativa de "isolar" o pensamento mítico, do "momento filosófico", ou seja, mensurar o aparecimento do "lógos" como sendo o surgimento da filosofia. Como observamos na argumentação anterior, essa súbita passagem de um pensar rudimentar e primitivo atribuído ao mito, para um pensamento complexo e filosófico, não se sustenta. Em grande parte, porque a terminologia usada na mitologia permanece durante o pensar filosófico, como afirmamos a respeito da discussão sobre a arché, mas também porque a mitologia não trata apenas de simples narrativas ingênuas, mas de uma cosmologia, um ordenamento da compreensão de mundo, cheio de nuances e de detalhes, que revelam um pensar integrado à natureza.

Por isso, como nos diz Eliade (2002, p. 9) ao pensar a questão do mito como revelação de uma origem inaugural do mundo e das explicações desse mundo, por meio, da palavra poética o autor escreve: "o mito conta uma história sagrada; ele relata um acontecimento ocorrido no tempo primordial, o tempo fabuloso do "princípio".

Assim a filosofia não nasce de um rompimento brusco com o mito, mas de uma passagem lenta e imbricada própria do pensamento. Cassirer apresenta uma apreensão reveladora sobre o estreito caminho que liga o mito a filosofia.

O verdadeiro substrato do mito não é de pensamento, mas de sentimento. $\mathrm{O}$ mito e a religião primitiva não são, de maneira alguma, totalmente incoerentes, nem destituídos de senso ou de razão; mas sua coerência depende muito mais da unidade de sentimento que de regras lógicas. Esta unidade é um dos impulsos mais vigorosos e profundos do pensamento primitivo. Se o pensamento científico desejar descrever e explicar a realidade será obrigado a empregar seu método geral, que é o de classificação e sistematização. A vida é dividida em províncias separadas, que se distinguem nitidamente uma da outra. As fronteiras entre os reinos das plantas, dos animais, do homem - as diferenças entre as espécies, famílias e gêneros - são fundamentais e indeléveis. Mas a mente primitiva ignora e rejeita todas elas. Sua visão da vida é sintética e não analítica; não se acha dividida em classes e subclasses. É 
percebida como um todo ininterrupto e contínuo, que não admite distinções bem definidas e incisivas. Os limites entre as diferentes esferas não são barreiras intransponíveis, mas fluentes e flutuantes. Não existe diferença específica entre os vários reinos da vida. Nada possui forma definida, invariável, estática: por súbita metamorfose qualquer coisa pode transformar-se em qualquer coisa. Se existe algum traço característico e notável do mundo mítico, alguma lei que o governe - é a da metamorfose. Mesmo assim, dificilmente poderemos explicar a instabilidade do mundo mítico pela incapacidade do homem primitivo de apreender as diferenças empíricas das coisas. Neste sentido, o selvagem, muito frequentemente, demonstra sua superioridade em relação ao homem civilizado, por ser suscetível a inúmeros traços distintivos, que escapam à nossa atenção. (CASSIRER, 1977, p. 134).

Cassirer, menciona acima, sobre o caráter cientifico do homem moderno em contraposição ao pensar mítico, próprio do selvagem. Mas o autor alemão encaminha a discussão para o caráter objetivado do pensar científico, a linguagem e a arte em si, não podem ser conhecidas em sua estrutura íntima, devido ao seu caráter dinâmico, que também é indefinido, por conta disso o autor aponta para o papel que desempenha o mito para o pensar simbólico do mundo empírico, fato esse que o homem primitivo não detém, por conta, de sua consciência da inconstância da vida, porém, o homem moderno detém das ciências naturais e de sua função comum para fugir do caráter primitivo da vida selvagem. No entanto, o caráter primitivo, de modo algum denota uma inferioridade, pois é capaz de lidar com a inconstância e as mudanças próprias da natureza, diferente do homem moderno que a sujeita a sua chancela.

O mito expressa essa natureza da metamorfose, quando nos referimos a percepção ela vai muito além daquilo que é percebido, por conta disso, é que o mundo físico se encontra submerso ao sentido dinâmico, enquadrando o homem dentro desse espaço cercado por movimentos imprevisíveis. O mito representa uma forma primária de pensar o mundo, emitida por uma cultura original, que se abstém da sistematização e de regras lógicas para transformar em linguagem as formas simbólicas.

O homem e a vida não são algo determinado, é isso que expressa o mito, e as narrativas primitivas simbólicas, a natureza espelha a metamorfose trabalhada pelo mito. Portanto, o homem não é algo fixo e determinado, mas sujeito aos "inúmeros traços distintivos" a tragédia é um traço distintivo que emancipa o homem, e torna a verdade compreensível para o pensar interior do homem.

Chegamos aqui em um momento fundamental, no qual identificamos o pensar literário, na mesma ordem de importância do pensar filosófico, se não ocorre ruptura, mas sim uma extensão do pensar mítico ao pensar filosófico, vemos que a tragédia, de um modo geral, herdou do pensar mítico uma característica do pensar filosófico clássico, que trabalhava com a noção de metáforas além da alegoria. Esse fato é verificável em inúmeros discursos, como em Sócrates e Platão que trabalhavam no 
mesmo sentido do pensar mítico, diferenciando-os apenas no foco dos objetos do discurso.

Por isso, devemos encarar a tragédia grega como um discurso que revela algo velado, um discurso que nos fala de modo indireto, discurso que suscita uma hermenêutica apropriada. A falta de uma motivação profunda para se apropriar dos textos antigos, construiu inúmeras críticas a tais obras, como por exemplo, aos textos de Hesíodo e Homero, que hoje nos fornecem uma visão peculiar do mundo grego antigo, porém como diz Brisson (2014, p. 64): "É praticamente impossível pronunciarse sobre as origens da alegoria, pois, como se verá, os testemunhos acerca daqueles que primeiramente se puseram a exercer essa prática são muito posteriores à época que eles evocam".

Assim sendo, dificilmente se pode mensurar o aspecto mítico e racional dos discursos ditos "antigos", construir críticas ou procurar mensurar uma interpretação unívoca e literalmente análoga ao pensar clássico, principalmente, ao analisarmos os escritos de Hesíodo e Homero, entre outros. O pensar filosófico não é antípoda do mito e o mito não é uma fase primitiva do pensamento racional, ambos são frutos históricos do homem e, se permanece uma dificuldade na interpretação dos textos antigos, por nos escapar o horizonte de compreensão no qual eles nasceram, nossa tarefa é de reiteradamente retomá-los, pois, cada um deles descrevem um ponto peculiar, na formação do ocidente.

\section{Referências}

ABBAGNANO, Nicola. Dicionário de Filosofia. São Paulo: Martins Fontes, 1998.

ARISTÓTELES. Metafísica. Tradução de Leonel Vallandro. Porto Alegre: Globo, 1969.

BORNHEIM, Gerd. Os filósofos pré-socráticos. São Paulo: Cultrix, 1998.

BRISSON, Luc. Introdução à Filosofia do Mito. Tradução de José Carlos Baracat Junior. 2. ed.

São Paulo: Paulus, 2014.

CASSIRER, Ernst. Antropologia Filosófica. Tradução de Vicente Felix de Queiroz. São Paulo:

Mestre Jou, 1972.

HESíODO. Teogonia: Origem dos deuses. 3. ed. São Paulo: Iluminuras, 1995.

JAEGER, Werner. Paideia: a formação do homem grego. Tradução Artur M. Parreira. 6. ed. São Paulo: Martins Fontes, 2013.

JARESKY, Kris. Mito e Lógos em Platão. São Paulo: Paulus, 2015.

Submissão: 13.07.2017 / Aceite: 16. o8. 2017 